rupted two hundred times a second by a revolving disk with an aperture in it. These rays are directed into the gas chamber containing the mixture to be tested. The chamber has a window at one end to admit rays and a microphone at the other. When infra-red rays enter the gas mixture, its pressure is increased by heat generated by absorption and the microphone membrane is depressed. When the flow of infra-red rays is interrupted, the gas expands and the microphone membrane returns to normal. Pulsations of the microphone are ampliffed, the current is rectifled and measured on a needle galvanometer. Deflexions of the galvanometer needle therefore correspond to the quantity of gas in the air of the experimental chamber. The connexion between the galvanometer readings and quantity of gas in the chamber can be determined experimentally by using known concentrations.

The optical-acoustic gas analyser can also sometimes be used to determine the presence of several different gases in the atmosphere, and also to measure the contents of mixtures of gases which do not contain air. The instrument is practically instantaneous in action
and so sensitive that it will determine the presence of ether in a concentration of 0.1 milligram in a litre of air.

Moscow. May 16.

MARK VENGEROV

(By cable.)

Production of a Derivative of $5: 6$ Anhydroglucose by the Hydrolysis of an Ethereal Sulphate

ALTHOUGH it is now well established ${ }^{1,2,3}$ that the alkaline hydrolysis of suitably substituted hexoses carrying sulphate groups on either the 3 or 6 positions readily yields $3: 6$ anhydrohexose derivatives, all our attempts to obtain evidence for the formation of ethylene oxide rings have been, until recently, unsuccessful, in marked contrast to the behaviour of the toluene- $p$-sulphonates ${ }^{4}$. It is now evident that this has been due largely to the fact that the barium salts of the sugar ethereal sulphates investigated were insoluble in organic solvents and the hydrolyses had, in consequence, to be carried out in aqueous media. Under such conditions experimental difficulties arise, for any ethylene oxide derivatives which may have been formed would be hydrolysed with accompanying Walden inversions ${ }^{4}$. Thus since the ethylene oxide ring formation would also involve a Walden inversion on the carbon atom where the sulphate group was originally attached, the production in recognizable quantity of a derivative of a hexose different from that in the original starting material depends on the relative ease of fission of the two ethylene oxide ring linkages. Thus the hydrolysis of a derivative of glucofuranose-3-sulphate could yield a $2: 3$ anhydroallofuranose, which might give either a gluco- or an aitrofuranose derivative, or both ${ }^{3}$.

This difficulty has now been overcome by the choice of barium 1:2-monoacetone-3-methyl-glucofuranose-6-sulphate as starting material. Treatment in methanolic solution with sodium methoxide at $40^{\circ}$ for 3 hours vields $1: 2$-monoacetone-3-methyl-5 :6 anhydro$40^{\circ}$ for 3 hours yields $1: 2$-monoacetone-3-methyl-5:6 anhydroglucofuranose, the structure of which is proved by further treatment
with sodium methoxide at $90^{\circ}$ and hydrolysis to give crystalline $3: 6$-dimethylglucose $[\alpha]_{D}^{10^{\circ}}+61^{\circ}$ (equilibrium in water), m.p. $116^{\circ}$, not depressed by an authentic specimen kindly provided by Dr. D. J. Bell ${ }^{5}$

It is clear, therefore, that when conditions are suitable and the formation of a $3: 6$-anhydro ring is prevented by substitution, the hydrolysis of an ethereal sulphate readily gives rise to the production of an ethylene oxide ring, as in the case of the toluene- $p$-sulphonates. It is to be expected, therefore, that when the sulphate substituent is located on an asymmetric carbon atom with an adjacent hydroxyl group in the trans position, an ethylene oxide ring with accompanying Walden inversion will be produced on hydrolysis. Experiments are now in progress to test this hypothesis, which, if substantiated, will of sugers in Nature through the intermediate formation of ethereal of sugers
sulphates.

Department of Chemistry,
University of Edinburgh.

E. G. V. Percival May 28.

${ }^{1}$ Percival and Soutar, J. Chem Soc., 1475 (1940).

2 Duff and Percival, J. Chem. Soc., 830 (1941).

3 Percival, J. Chem. Soc., 119 (1945).

- Peat, Ann. Rep. Chem. Soc., 260 (1939).

s Bell, J. Chem. Soc., 1553 (1936)

\section{Experimental Data and 'Sufficient' Accuracy}

DURING a recent investigation on electron gun systems which,involved the collection of numerical data - the measurements of a certain distance- the problem arose as to how many data it was necessary to collect in order to achieve sufficient accuracy in the final result, which, in this case, was \pm 2 per cent. Use was made of the formula:

$$
\alpha=0.6745 \sqrt{\frac{\Sigma\left(x_{n}-M\right)^{2}}{n(n-1)}},
$$

where $a$ is the most probable error of the arithmetic mean $M$, of a series of $n$ observations $x_{1}, x_{2}$, etc.

A series of ten observations was made of the distance in question, on one system : the arithmetic mean of the observations 1 to $n$ was calculated for each value of $n$, and hence $a$ was determined for each of these sets. From the table of results it will be seen that $\alpha$ decreases with ascending values of $n$ until the minimum value permitted by the experimental conditions is reached. Although it appeared that seven observations were sufficient to give the desired accuracy, it was decided to use ten in case greater experimental difficulty wasencountered on other systems. This was justifled when the values of $a \sqrt{n}$, a measure

\begin{tabular}{|c|c|c|c|}
\hline$n$ & $x_{n}$ & $M$ & $\alpha$ \\
\hline 1 & $23 \cdot 9$ & $23 \cdot 9$ & - \\
2 & $20 \cdot 9$ & $22 \cdot 4$ & $1 \cdot 0$ \\
3 & $20 \cdot 0$ & $21 \cdot 6$ & $0 \cdot 8$ \\
4 & $22 \cdot 4$ & $21 \cdot 8$ & $0 \cdot 6$ \\
5 & $22 \cdot 7$ & $21 \cdot 9$ & $0 \cdot 5$ \\
6 & $24 \cdot 4$ & $22 \cdot 4$ & $0 \cdot 5$ \\
7 & $21 \cdot 7$ & $22 \cdot 3$ & $0 \cdot 4$ \\
8 & $25 \cdot 6$ & $22 \cdot 7$ & $0 \cdot 4$ \\
9 & $21 \cdot 7$ & $22 \cdot 6$ & $0 \cdot 4$ \\
10 & $20 \cdot 6$ & $22 \cdot 4$ & $0 \cdot 4$ \\
\hline
\end{tabular}

of the 'fineness' of the observations, were found to vary slightly on the next ten systems, although, in every case, the most probable error of $M$ was approximately the same as that required.

Standard Telephones and Cables, Ltd.

H. A. HUGHES

Footscray. Kent.
May 8 .

\section{Gesture as a Constant Factor in Linguistics}

IN May 1936, I wrote an article on $\mathrm{KU}$ in Chinese, which, through the courtesy of Prof. P. C. Chang, a Chinese philosopher then in London, Whe passed on to Prof. Y. R. Chao, the philologist, then in Nanking. Dictionary of Chinese and Sino-Japanese" (1923).

Of thirty-five words in $\mathrm{KU}$ - (or its variants, $\chi \mathrm{U}$, $\mathrm{KU}$, etc.), all except one were found to bear meanings which were simply connected with one or other of the natural gestural meanings of the mouth gesture.

I have heard from Prof. Alexander Johannesson that Prof. Chao (now in the United States) has written to him, referring to this article, and suggesting that the gesture theory may be "a constant factor for linguistic phenomena and not merely a theory to explain the history of words'

With this suggestion I would personally agree-in view of the comparative frequency of appropriate mouth gesture in children's invented words, in new words (such as 'blimp') or in new meanings for old words (such as 'slump').

\section{Cottesmore Gardens, \\ Kensington, W.8.

$$
\text { June } 10 \text {. }
$$

R. A. S. PAGET

\section{Growth Curves}

IN NATURE of January 19, 1946, there is a short communication by Prof. W. G. Burgers on " 'Stimulation Crystals' and Twin-formation in Recrystallized Aluminium,". As indicated in ref. 1 to this communication, the analysis of the forms of the grain boundaries was carried out y Sandee and appears in the Dutch journal Physica in 1942 .

I should like to direct attention to the remarkable similarity between the curves analysed by Sandee and those discussed in a paper by me in the Edinburgh Mathematical Notes of December 1945 entitled "Curves Formed by Colonies of Micro-organisms Growing on a Plane Surface". My paper is a more detailed mathematical analysis a rising out of work which I undertook at the University of Glasgow in connexion with a communication by Drs. G. Pontecorvo and A. R. Gemmell, entitled "Colonies of Penicillium notatum and other Moulds as Models for the Study of Population Genetics" and published in Nature of October 28,1944

The curves analysed in these two separate fields, of physical chemistry and the growth of living organisms. are identical. This rather remarkable fact may be of mutual help to workers in both fields, while at the same time it offers scope for some interesting philosophical deductions.

c/o J. Rössler,

AgNes H. WADDELL

Bredovska 15. Prague II. May 16.

Postal Communication with the U.S.S.R.

IN September 1945 I had the privilege, as president of the Genetical Society, of inviting four distinguished Russian geneticists to a conference in London, to take place on October 31 . I received a reply from one of them in February of this year, and on May 30 a reply
from another which runs as follows:

Moscow, May 3, 1946.

Dear Dr. Darlington,

I am very grateful to you for your invitation to the Conference of the Genetical Society dated September 19th, 1945. Unfortunately, it reached me on the 27th of [April] 1946, so that I couldn't possibly avail myself of the opportunity. I do not lose hope of meeting you in the near future at the next session of your Society.

(Sgn.) N.'P. Dubinin.

The letter bore the air mail post-mark of May 19, my letter having evidently been received on April 27 and replied to six days later. I have received no reply from the other two invited guests.

Since I find communication with my Russian colleagues so difficult, especially with my old friends Lewitzky and Karpechenko, may I be permitted to make use of these columns to say how much I, and my colleagues in Great Britain, look forward to the renewal of our scientific intercourse?

John Innes Horticultural Institution,

C. D. DARLINGTON 